\title{
Comparing the Effects of Acupressure at the Hugo Point and Hyoscine on the Duration of Labor Stages and Fetal- neonatal Outcomes in Nulliparous Women: A Controlled Randomized Clinical Trial
}

\author{
Solmaz Babazadeh Topraghlou ${ }^{\circledR}$, Fahimeh Sehhatie Shafaie $^{2^{*}}$, Mojgan Mirghafourvand $^{3}$, Narges Salehi $^{4}$
}

\begin{abstract}
Objectives: The shortened duration of labor without creating major complications is considered ideal for the mother and infant while prolonged labor is accompanied by maternal and fetal consequences. Considering its importance, the purpose of this study was to compare the effects of acupressure at the Hugo point and hyoscine on the duration of labor stages and fetal-neonatal outcomes in nulliparous women.

Methods: This controlled randomized clinical trial was conducted on 162 nulliparous women who referred to Ardabil Sabalan Hospital in 2017. Participants were divided into Hugo acupressure, hyoscine, and control groups by means of randomized blocks, each containing 54 nulliparous women. In the Hugo group, the pressure exerted on the Hugo point at $5 \mathrm{~cm}$ dilatation and in the hyoscine group, the hyoscine was injected intramuscularly at $5 \mathrm{~cm}$ dilatation. Data were analyzed using one-way ANOVA, KruskalWallis, Fisher exact, and chi-square tests.

Results: The mean (SD) duration of the active phase of labor was 137.0 (15.1), 143.3 (172), and 187.7 (24.7) minutes in the Hugo, hyoscine, and control groups, respectively. In addition, the mean (SD) duration of the second stage of labor in the above-mentioned groups was 39.5 (8.5), $52.4(15.0)$, and 58.3 (8.7) minutes, respectively $(P<0.001)$.

Conclusions: Overall, the implementation of acupressure at the Hugo point led to a greater reduction in the duration of labor stages compared to hyoscine infusion without imposing the side-effects on mother.

Keywords: Nulliparous, Hugo point acupressure, Hyoscine, Duration of labor stages, Fetal-neonatal outcomes
\end{abstract}

\section{Introduction}

Labor is regarded as one of the important events that women experience and always remember. Therefore, the negative experience of labor for a mother and her family has unfavorable emotional and mental effects $(1,2)$. In addition, prolonged labor is a crucial clinical problem in modern midwifery and creates numerous challenges for mother and infant (3) such that shortening the duration of labor is considered as one of the ongoing concerns of the specialists (4).

Prolonged labor, bleeding, and infection are the most essential causes of maternal mortality in labor and early post-delivery days (5). Further, prolonged duration of the first stage of labor is accompanied by fetal (e.g., pressure on the head, disrupted oxygen supply, low Apgar, and ultimately, fetal mortality) and maternal (e.g., bleeding, post-delivery infection, anxiety-induced confusion, sleeplessness, and fatigue) complications (6). The prevalence of prolonged labor is 3-8 percent, which is three times higher in nulliparous women compared to multiparous women (7). Given the outcomes of prolonged labor, difficult labor is the most common cause of going through primary cesarean (C) section (8).

To reduce the duration of the first stage of labor and prevent prolonged labor complications, various solutions are suggested such as using oxytocin, hyoscine, and pethidine medicines. However, these might create different side-effects like dry mouth, facial flushing, dry skin, photophobia, urge incontinence, urinary retention, and constipation (9).

Hyoscine n-butylbromide is a muscarinic antagonist which is used for cervical spasm relief with a total clearance of $1.2 \mathrm{~L} / \mathrm{min}$. Its side-effects include dry mouth, facial flushing, dry skin, photophobia, urge incontinence, urinary retention, and constipation (10). Some studies reported a $30 \%-40 \%$ reduction in the duration of labor following hyoscine administration $(11,12)$. The results of Aggarwal et al (13) and Sirohiwal et al (11) showed that hyoscine shortened the duration of the first stage of labor.

The use of non-drug methods (e.g., acupressure) is another way of reducing the duration of labor, which is preferred over drug methods because of its 
inexpensiveness, easy administration, non-invasiveness, self-confidence building, and client engagement (14). Acupressure is a branch of acupuncture in which pressure by hand or fingers is used instead of the needle (15). There are several pressure points in the body for labor progress and it is believed that the stimulation of such points provokes uterine contractions and as a result, accelerates the labor and creates energy balance while reducing labor pain (16). The points used for inducing and handling the labor include SP9 'GB21, BL32, LI4, BL31, LV3, SP6, and BL67. Hugo point (Figure 1) is among the important points in colon energy channel located at the back of the hand between the first and second bones of the palm next to the second metacarpal base (17) and is used to boost blood flow, reduce spasm and pain, and help fetal descent (18).

Salehian et al showed that pressure on the Hugo point would reduce the duration of the active phase and the second stage of labor in nulliparous women (19). Chao et al also reported a reduction in the duration of the first labor stage in Hugo pressure intervention group (20). Achieving some sort of arrangements to shorten labor duration, especially with non-invasive methods seems necessary. Furthermore, reducing the duration of labor probably leads to a decrease in the extent of pain that the mother tolerates in this regard. It is rational to argue that the rate of emergency $\mathrm{C}$-section would reduce with the shortened duration of labor.

As mentioned earlier, hyoscine medicine, which is used in many birthing centers, is accompanied by several sideeffects. Since no side-effect is reported in the literature for the Hugo pressure and because no research is conducted to compare a drug method (hyoscine) with acupressure (Hugo point), the present study aimed to compare these two methods in order to develop a protocol based on the effects and side-effects of both interventions and thus to reduce the duration of labor without imposing complications on mother and prevent prolonged labor That causes many maternal and fetal problems.

\section{Materials and Methods}

Research Design and Participants

The current double-blinded controlled randomized clinical trial was performed during four months (AugustNovember 2017) in Ardabil Sabalan hospital. It should be noted that the participants, as well as data collectors and analyzers had no knowledge of subject placement in the groups. Base on the purpose of this clinical trial, the duration of labor stages and fetal-neonatal outcomes were compared in both Hugo acupressure (L14) and hyoscine groups among nulliparous women referring to Ardabil Sabalan hospital. This hospital is a 160 -bed medical center affiliated with Iranian Social Security Organizations and includes 13 wards and the present study was conducted in the delivery rooms of this hospital.

The inclusion criteria were as follows:

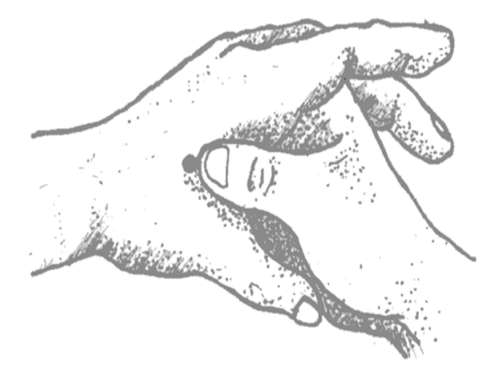

Figure 1. Hugo point (LI4)

- Nulliparous pregnant women (18-35 years old) at the gestational age of 37-42 weeks (based on last menstrual period or less than 12 weeks ultrasound);

- Singleton pregnancy with a cephalic presentation;

- Intact membranes in the preliminary examination or a 6-hour interval after the rupture;

- Spontaneous uterine contractions;

- Low-risk pregnancy, namely, with no chronic disease including cardiac diseases, high blood pressure, pulmonary diseases, diabetes, anemia, genitourinary tract infections, thyroid-related diseases, as well as no history of recurrent miscarriage (3 times or more), embryonic death, and the bleeding of any abnormal case at the time of referral;

- No maternal and/or fetal illness and complications as claimed by the pregnant mother;

- The conformity of pelvic diameters to fetal head based on vaginal examination;

- $\quad$ Height > $145 \mathrm{~cm}$;

- $\quad$ No damage to Hugo point (Figure 1);

- No communication disorder (i.e., deafness and blindness).

The sample size was calculated according to studies by Sehhatie-Shafaie et al (21) and Ebrahimzadeh et al (22). Given $\mathrm{ml}=7$ (the duration of active labor phase) and a $25 \%$ decrease in the duration of the active phase of labor following the intervention $\left(\mathrm{m}^{2}=5.25\right), \mathrm{sd} 1=\mathrm{sd} 2=3.44$, $\alpha=0.05$, and power $=80 \%$, the sample size was estimated at 49 individuals and then, the final sample size was set at 54 individuals in each group by considering a $10 \%$ attrition rate.

\section{Sampling}

Sampling began after the research proposal was approved by the Research Council and the Ethics Committee of the Deputy of Research at Tabriz University of Medical Sciences (under the ethical code of IR.TBZMED. REC.1396.288) and registered at Iranian Registry of Clinical Trials (identifier: IRCT201709293027N39; https://www.irct.ir/trial/3009). Moreover, the preliminary sampling was of convenience type so that nulliparous women referring to the delivery rooms of the hospital for childbirth and meeting the inclusion criteria were selected and provided with the description of the research goals. 
Those who were interested in participation gave written informed consent and completed the demographic information questionnaire.

\section{Randomization and Intervention}

The samples were assigned to 3 groups of 56 women (i.e., hyoscine, Hugo pressure, and control groups) using the randomized blocks with three and six blocks and 1:1:1 allocation ratio in computer software (http://www. random.org)). Additionally, the type of intervention was written down on a piece of paper and put in opaque envelopes in the order of numbering in order to hide the allocation. Similarly, random allocation and hiding were applied by an individual who was not involved in sampling and data collection procedures.

The pressure was exerted vertically on the Hugo point at $5 \mathrm{~cm}$ dilatation with the start of each contraction. In addition, an acupuncture specialist trained the research assistant about how to find the Hugo point and to exert pressure and the extent of pressure. Therefore, the assistant exerted the pressure on the Hugo point so that at $5 \mathrm{~cm}$ dilatation and with the start of a contraction, gentle pressure was exerted on the Hugo point for 30 seconds with a gradual increase in the pressure until the client felt the numbness, heaviness, and tension around the point. Next, she held her thumb on the point for one minute and then the pressure lifted gradually, therefore, the point was pressure-free in 30 seconds. After a five-minute break, the whole process continued for 20 minutes during the contractions. Then, the pressure lifted completely until $6 \mathrm{~cm}$ dilatation and all the above-mentioned processes were exactly performed at 6,8 , and $10 \mathrm{~cm}$ dilatation. The duration of the active phase (from 4 to $10 \mathrm{~cm}$ dilatation), the second stage of labor (from full dilatation to delivery) measured by vaginal examination, and the third stage of labor (from delivery to placental exit) was recorded in the checklist and partograph form.

For the hyoscine group, following vaginal examinations for assessing cervical dilatation, $20 \mathrm{mg}$ of hyoscine was injected intramuscularly at the onset of the active phase of labor (5 cm dilatation) and recorded in the checklist while the control group received the routine cares. Fetalneonatal outcomes (i.e., tachycardia, bradycardia, no beat-to-beat variability, first and fifth minute Apgar, and the need for infant resuscitation) were recorded in the checklist for all three groups. The hyoscine side-effects were also recorded in the checklist for the hyoscine group. Finally, demographic information questionnaire was used to collect the participants' information.

\section{Data Analysis}

The data were analyzed using SPSS version 24 . To this end, the normality of the quantitative variables was checked using the Kolmogorov-Smirnov test and the variable named "the duration of the third stage of labor" was found to be abnormal. Further, Chi-square, round Chi-square, one-way ANOVA, and Fisher exact tests were utilized to compare the demographic information of the three groups. Likewise, one-way ANOVA was applied to compare the average duration of the active phase and the second stage of labor among the groups, followed by employing the Kruskal-Wallis test to compare the duration of the third stage of labor. Eventually, the Kruskal-Wallis and Fisher exact tests were used to compare fetal-neonatal outcomes. The significance level was considered at $P<0.05$.

\section{Results}

This research was initiated in February 2017 and ended in November 2017 and a number of 186 women were assessed according to inclusion and exclusion criteria. Totally, 24 women were unqualified in terms of the number of parity, gestational age, and the mother's age while 162 women were selected based on the aim of the research. Furthermore, 2 women in the hyoscine group and 1 woman in the control group had cesarean section surgery due to the lack of progress in labor (Figure 2).

As regards demographic information, no statistically significant difference was found among the groups except for the spousal employment $(P>0.05)$. The mean (SD) age of the participants and the mean (SD) gestational age was 23.4 (4.0) years and 38.7 (1.0) weeks, respectively. Moreover, the majority of women in Hugo (72.2\%), hyoscine $(74.1 \%)$, and control $(63.0 \%)$ groups resided in the city. Most women in the Hugo (98.1\%), hyoscine (94.4\%), and control (92.6\%) groups were housewives as well. In terms of spousal employment, $3.7 \%, 1.9 \%$, and $18.5 \%$ of spouses in the Hugo, hyoscine, and control groups were unemployed, respectively. Additionally, the majority of women in the Hugo (61.1\%), hyoscine (70.4\%), and control (74.4\%) groups had no history of abortion (Table 1).

According to the results of one-way ANOVA, the duration of the active phase, second stage, and the whole labor process showed a statistically significant difference $(P<0.001)$ while the third stage of labor was not significantly different based on Kruskal-Wallis test $(P=0.990)$. In the Hugo group, the mean (SD) duration of the active phase, second stage, third stage, along with the whole process of labor was reported as 137.0 (15.1), 39.5 (8.5), 6.3 (4.2), and 176.1 (17.5) minutes, respectively. In relation to hyoscine group, the mean (SD) duration of the active phase, second stage, third stage, and the whole process of labor was estimated at 143.3 (17.2), 52.4 (15.0), 6.2 (3.6), and 193.3 (19.0) minutes, respectively. In the control group, the mean (SD) duration of the active phase, second stage, third stage, and the whole process of labor was reported as 187.7 (24.7), 58.3 (8.7), 6.4 (4.2), and 246.0 (26.6) minutes, respectively (Table 2 ).

The first minute Apgar was above 7 in most infants of all three groups, which was statistically significant based on the results of the Kruskal-Wallis test $(P=0.044)$. In addition, the fifth minute Apgar was 10 in all the infants 


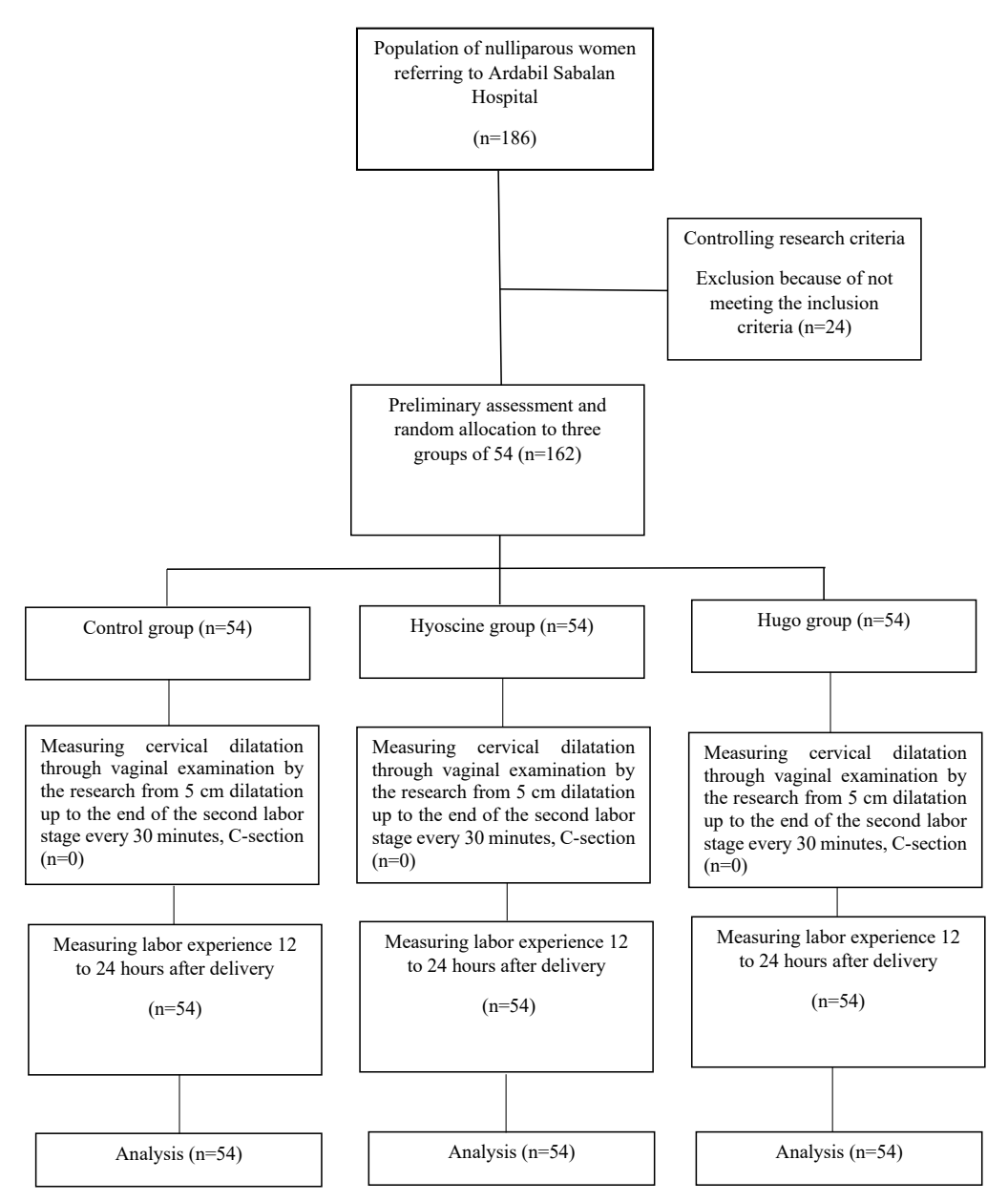

Figure 2. Flowchart of the Stages and Procedure of the Research.

of the three groups. In terms of fetal bradycardia, there was a statistically significant difference among the three groups $(P=0.007)$. Conversely, no statistically significant difference was found among the three groups in terms of the frequency of the need for resuscitation $(P=0.183)$, fetal tachycardia $(P=0.100)$, and the fetal heart rate beat-tobeat variability $(P=1.00)$, the related details are provided in Table 3.

In the hyoscine group, the participants had a feeling of dizziness (6.8\%), tachycardia (0.6\%), dry lips (9.9\%), facial flushing $(9.9 \%)$, headache (10.5\%), nausea $(19.8 \%)$, vertigo (3.7\%), reduced vision (33.3\%), and drowsiness (9.9\%).

\section{Discussion}

The results indicated that pressure on the Hugo point led to a greater reduction in the duration of labor compared to hyoscine infusion without imposing any side-effects on the mother. There was a statistically significant difference in fetal-neonatal outcomes only in terms of fetal bradycardia and first minute Apgar in the three groups.

In a study by Heydari et al (23), the duration of the second stage was not significantly different in the two groups ( $P=0.521$ ), which is not consistent with the results of the present study that might be attributed to the administration of the intervention at different dilatations.

Kim et al (24) examined the effect of pressure at the Hugo and Saninjiao points on the duration of labor and found that pressure on these points reduced the duration of labor in the LI4 and SP6 groups compared to the control group $(P<0.05)$, which is in line with our findings.

To explore the effects of L14 acupressure on the duration of labor stages, maternal physiological indicators, and infant Apgar score, Hamidzadeh et al conducted a quasiexperimental randomized clinical trial on 100 full-term pregnant women, in the active phase of labor, who referred to Shahrood Fatemieh hospital, Iran. The samples were randomly divided into experimental (acupressure, $\mathrm{n}=50$ ) and control (touching, $\mathrm{n}=50$ ) groups. The former group received 20-minute simultaneous acupressure at the L14 point on both hands and the latter one received touching the same way without any pressure. The results showed that L14 acupressure reduced the duration of the second stage of labor (25), which corroborates with the finding of our study. However, it had no effect on infant Apgar score which is contrary to the result of our study. 
Table 1. Demographic Information of the Participants in Research Groups (Hugo, Hyoscine, and Control)

\begin{tabular}{|c|c|c|c|c|}
\hline Variable & $\begin{array}{c}\text { Hugo } \\
n=54 \\
\text { No. (\%) }\end{array}$ & $\begin{array}{c}\text { Hyoscine } \\
n=54 \\
\text { No. (\%) }\end{array}$ & $\begin{array}{c}\text { Control } \\
n=54 \\
\text { No. (\%) }\end{array}$ & $P$ Value \\
\hline Age $(y)^{a}$ & (4.1) 24.0 & (3.7) 23.4 & (4.0) 22.9 & $0.397^{b}$ \\
\hline Gestational age (wk) & $(0.9) 38.5$ & (0.9) 38.7 & (1.0) 38.7 & $0.309^{b}$ \\
\hline Induction & & & & $0.467^{c}$ \\
\hline uneducated & (3.7) 2 & $(0.0) 0$ & (3.7) 2 & \\
\hline Elementary and middle school & $(42.6) 23$ & $(70.4) 38$ & $(40.7) 22$ & \\
\hline Diploma & $(27.8) 15$ & $(27.8) 15$ & $(42.6) 23$ & \\
\hline Tertiary education & $(5.6) 3$ & (1.9) 1 & (13.0) 7 & \\
\hline Spousal education & & & & $0.581^{c}$ \\
\hline Uneducated & $(0.0) 0$ & (1.9) 1 & $(0.0) 0$ & \\
\hline Elementary and middle school & (39.9) 21 & $(44.4) 24$ & $(42.6) 23$ & \\
\hline Diploma & $(51.9) 28$ & $(44.4) 24$ & $(37.0) 20$ & \\
\hline Tertiary education & (9.3) 5 & (9.3) 5 & $(20.4) 11$ & \\
\hline Residence & & & & $0.404^{d}$ \\
\hline City & $(72.2) 39$ & $(74.1) 40$ & $(63.0) 34$ & \\
\hline Village & $(27.8) 15$ & $(25.9) 14$ & $(37.0) 20$ & \\
\hline Employment & & & & $0.136^{e}$ \\
\hline Housewife & $(98.1) 53$ & $(94.4) 51$ & (92.6) 50 & \\
\hline Employed & (1.9) 1 & (5.6) 3 & (7.4) 4 & \\
\hline Spousal employment & & & & $0.001^{e}$ \\
\hline Self-employed & $(87.0) 47$ & $(92.5) 49$ & (51.9) 28 & \\
\hline Civil servant & (9.3) 5 & (5.7) 3 & $(29.6) 16$ & \\
\hline Unemployment & (3.7) 2 & (1.9) 1 & (18.5) 10 & \\
\hline History of abortion & & & & $0.500^{e}$ \\
\hline No & $(61.1) 33$ & $(70.4) 38$ & $(74.4) 38$ & \\
\hline Once & (31.5) 17 & $(24.1) 13$ & $(24.1) 13$ & \\
\hline Twice & (1.9) 1 & (5.6) 33 & (1.9) 1 & \\
\hline Three times & $(5.6) 3$ & $(0.0) 0$ & (3.7) 2 & \\
\hline
\end{tabular}

${ }^{a}$ Numbers represent mean (SD); ${ }^{\text {b }}$ One-way ANOVA; ${ }^{\mathrm{c}}$ Round chi-square test; ${ }^{\mathrm{d}}$ Chi-square test; ${ }^{\mathrm{e}}$ Fisher exact test.

Table 2. Comparison of the Means and Standard Deviations of the Duration of Labor Stages in Research Groups (Hugo, hyoscine, and control)

\begin{tabular}{|c|c|c|c|c|c|c|c|}
\hline \multirow{2}{*}{ Variable } & \multicolumn{2}{|c|}{ Hugo $(n=54)$} & \multicolumn{2}{|c|}{ Hyoscine $(n=54)$} & \multicolumn{2}{|c|}{ Control $(n=54)$} & \multirow{2}{*}{$P$ Value } \\
\hline & Median (25-75) & Mean (SD) & Median (25-75) & Mean (SD) & Median (25-75) & Mean (SD) & \\
\hline $\begin{array}{l}\text { Active phase of } \\
\text { labor (min) }\end{array}$ & $137(127-146)$ & $137.0(15.1)$ & $141(132-151)$ & $143.3(17.2)$ & $188(171-206)$ & $187.7(24.7)$ & $<0.001^{a}$ \\
\hline $\begin{array}{l}\text { Second stage of } \\
\text { labor (min) }\end{array}$ & $40(33-45)$ & $39.5(8.5)$ & $49(45-58)$ & $52.4(15.0)$ & $58(52-63)$ & $58.3(8.7)$ & $<0.001^{a}$ \\
\hline $\begin{array}{l}\text { Third stage of } \\
\text { labor (min) }\end{array}$ & $5(4-8)$ & $6.3(4.2)$ & $5(4-8)$ & $6.2(3.6)$ & $6(3-8)$ & $6.4(4.2)$ & $0.990^{\mathrm{b}}$ \\
\hline $\begin{array}{l}\text { Total duration of } \\
\text { labor (min) }\end{array}$ & $176(161-188)$ & $176.1(17.5)$ & $190(180-201)$ & $193.3(19.0)$ & $247(227-263)$ & $246.0(26.6)$ & $<0.001^{\text {a }}$ \\
\hline
\end{tabular}

Note. Numbers are in minute.

${ }^{a}$ One-way ANOVA; ${ }^{b}$ Kruskal-Wallis test.

Likewise, Kaviani et al evaluated 165 nulliparous women in order to compare the effects of acupressure and ice massage at the L14 point on the intensity of pain, the level of anxiety, and the duration of labor. The samples were categorized into acupressure, ice massage, and control groups each including 55 women. The intervention began at $3-4 \mathrm{~cm}$ dilatation at L14 point and the length of the intervention was 30 minutes. Both acupressure and ice massage reduced the pain, the duration of labor, and the level of anxiety in nulliparous women with the greater effect of the ice massage (26), which contradicts our finding.

In another study, Salehian et al (19), found that pressure on the Hugo point shortens the active phase and the second stage of labor $(P=0)$. This is in agreement with the result of the present study.

Similarly, investigating the effect of pressure at Saninjiao and Hugo points on the duration of labor, SehhatieShafaiei et al (21) compared the intervention group $(n=42)$, who received Saninjiao and Hugo acupressure, 
Table 3. Comparison of Fetal-Neonatal Outcomes in Intervention and Control Groups (Hugo, Hyoscine, and Control)

\begin{tabular}{|c|c|c|c|c|}
\hline \multirow[b]{2}{*}{ Neonatal Outcomes } & \multicolumn{3}{|c|}{ Groups } & \multirow[b]{2}{*}{$P$ Value } \\
\hline & $\begin{array}{c}\text { Hugo }(n=54) \\
\text { No. }(\%)\end{array}$ & $\begin{array}{c}\text { Hyoscine }(n=54) \\
\text { No. }(\%)\end{array}$ & $\begin{array}{c}\text { Control }(n=54) \\
\text { No. }(\%)\end{array}$ & \\
\hline First minute Apgar & & & & $0.044^{b}$ \\
\hline 7 & $0(0)$ & $0(0)$ & $1(1.9)$ & \\
\hline 8 & $5(9.3)$ & $9(16.7)$ & $17(31.5)$ & \\
\hline 9 & $47(87.0)$ & $4(74.1)$ & $32(59.3)$ & \\
\hline 10 & $2(3.7)$ & $5(9.3)$ & $4(7.4)$ & \\
\hline Need for resuscitation & & & & $0.183^{c}$ \\
\hline No & $52(96.3)$ & $46(85.2)$ & $47(87.0)$ & \\
\hline Oxygen only & $2(3.7)$ & $7(13.0)$ & $7(13.0)$ & \\
\hline Use of bag valve mask (p.p.v) & $0(0)$ & $1(1.9)$ & $0(0)$ & \\
\hline Tachycardia & & & & $0.100^{c}$ \\
\hline No & $53(98.1)$ & $52(98.1)$ & $52(96.3)$ & \\
\hline In the active phase of labor & $0(0)$ & $0(0)$ & $0(0)$ & \\
\hline In the second stage of labor & $1(1.9)$ & $1(1.9)$ & $2(3.7)$ & \\
\hline Bradycardia & & & & $0.007^{c}$ \\
\hline No & $53(98.1)$ & $45(83.3)$ & $52(96.3)$ & \\
\hline In the active phase of labor & $1(1.9)$ & $2(3.7)$ & $0(0)$ & \\
\hline In the second stage of labor & $0(0)$ & $7(13.0)$ & $2(3.7)$ & \\
\hline Disappearance of beat-to-beat variability & & & & $1.00^{c}$ \\
\hline No & $54(100.0)$ & $53(98.1)$ & $54(100.0)$ & \\
\hline In the active phase of labor & $0(0)$ & $0(0)$ & $0(0)$ & \\
\hline In the second stage of labor & $0(0)$ & $1(1.9)$ & $0(0)$ & \\
\hline
\end{tabular}

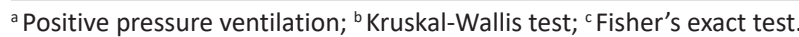

with the control group $(n=42)$. Based on their reports, shortened active phase $(P=0.001)$ and the second stage of labor $(P=0.008)$ was observed in the intervention group, which was statistically significant and consistent with our results.

Further, Ebrahimzadeh et al (22) conducted a study to compare the effect of hyoscine and promethazine on the duration of the active phase of labor and found no significant difference in the first and fifth minute Apgar scores between the study groups $(P>0.05)$. However, this is not in conformity with the findings of our study and such a difference could be attributed to their research design which only included medicine but not acupressure.

Sirohiwal et al evaluated the effect of hyoscine suppository on labor in India and administered hyoscine suppository (Buscupan) to 100 pregnant women at $3 \mathrm{~cm}$ dilatation and compared the results with a 100-sample control group. However, no sign of any side-effects was reported for hyoscine in this study (11), which is contrary to our results and is probably due to hyoscine administration method since the present study used an intramuscular injection in this regard.

Makvandi et al also examined the effect of hyoscine rectal suppository on labor in nulliparous women in Ahvaz (Iran) and found that the rate of tachycardia and bradycardia was equal and insignificant in both intervention and control groups (27). This is consistent with the findings of the current study except for the fact that the rate of bradycardia was significant.

As shown, none of the above-mentioned studies compared Hugo acupressure and hyoscine medicine while Hugo acupressure can reduce the duration of labor stages more without imposing any side-effects on mother. The present research was conducted in a public hospital where most of the participants were of middle and lower middle social class and education, which is considered as its limitation. Therefore, researchers are recommended to conduct a similar study in private hospitals and compare Hugo acupressure and hyoscine in multiparous women, as well as Hugo and Saninjiao acupressure with hyoscine medicine.

\section{Conclusions}

In general, acupressure at the Hugo point (LI4) led to a greater reduction in the duration of labor stages compared to hyoscine. The side-effects of hyoscine (e.g., dizziness, vertigo, and blurred vision) were reported in the group who received hyoscine. Given its simplicity, the lack of complication, and its acceptability, Hugo acupressure can be used more extensively in delivery rooms. Finally, in line with the reduction of cesarean section surgeries, Hugo acupressure can be utilized more seriously as a routine measure in delivery rooms.

\section{Conflict of Interests}

Authors declare that they have no conflict of interests.

\section{Financial Support}

This study was financially supported by Tabriz University of Medical Sciences. 


\section{Acknowledgments}

The author would like to thank the authorities of the Faculty of Nursing and Midwifery and the Deputy of Research at Tabriz University of Medical Sciences. Further, special thanks go to the authorities, doctors, and midwives of Ardabil Sabalan Hospital, as well as all the mothers who helped us in this research.

\section{References}

1. Waters BL, Raisler J. Ice massage for the reduction of labor pain. J Midwifery Womens Health. 2003;48(5):317-321. doi:10.1016/S1526-9523(03)00277-0

2. Aziz M. Effect of rectal Hyoscine Butyl bromide suppositories on the first stage of labor. Int J Adv Res. 2014;2(4):128-135.

3. Nystedt A, Hogberg U, Lundman B. The negative birth experience of prolonged labour: a case-referent study. J Clin Nurs. 2005;14(5):579-586. doi:10.1111/j.13652702.2004.01105.x

4. Littleton LY, Engebretson JC. Maternal, neonatal, and women's health nursing. Pearson Education; 2002.

5. Garite TJ, Simpson KR. Intrauterine resuscitation during labor. Clin Obstet Gynecol. 2011;54(1):28-39. doi:10.1097/ GRF.0b013e31820a062b

6. Fraser WD, Cayer M, Soeder BM, Turcot L, Marcoux S. Risk factors for difficult delivery in nulliparas with epidural analgesia in second stage of labor. Obstet Gynecol. 2002;99(3):409-418.

7. Kolas T, Hofoss D, Daltveit AK, et al. Indications for cesarean deliveries in Norway. Am J Obstet Gynecol. 2003;188(4):864-870. doi:10.1067/mob.2003.217

8. Rowe-Murray HJ, Fisher JR. Operative intervention in delivery is associated with compromised early motherinfant interaction. BJOG. 2001;108(10):1068-1075.

9. Zeitlin D, Keller SE, Shiflett SC, Schleifer SJ, Bartlett JA. Immunological effects of massage therapy during academic stress. Psychosom Med. 2000;62(1):83-84.

10. Gupta B, Nellore V, Mittal S. Drotaverine hydrochloride versus hyoscine- $\mathrm{N}$-butylbromide in augmentation of labor. Int J Gynaecol Obstet. 2008;100(3):244-247. doi:10.1016/j. ijgo.2007.08.020

11. Sirohiwal D, Dahiya K, De M. Efficacy of hyoscine-Nbutyl bromide (Buscopan) suppositories as a cervical spasmolytic agent in labour. Aust N Z J Obstet Gynaecol. 2005;45(2):128-129. doi:10.1111/j.1479-828X.2005.00359.x

12. Samal S, Gupta U, Wable M. Buscopan (hyoscine-Nbutylbromide) in acceleration of labour. Ind Med Gaz. 1998;82:8-10.

13. Aggarwal P, Zutshi V, Batra S. Role of hyoscine N-butyl bromide (HBB, buscopan) as labor analgesic. Indian J Med Sci. 2008;62(5):179-184.

14. Field T. Pregnancy and labor alternative therapy research. Altern Ther Health Med. 2008;14(5):28-34.

15. Tournaire M, Theau-Yonneau A. Complementary and alternative approaches to pain relief during labor. Evid Based Complement Alternat Med. 2007;4(4):409-417. doi:10.1093/ecam/nem012

16. Cook A, Wilcox G. Pressuring pain. Alternative therapies for labor pain management. AWHONN Lifelines. 1997;1(2):36-41.

17. Jianguo Z. A newly compiled practical English-Chinese library of traditional Chinese medicine, house of tradinyional Chinese medicine. World J Acupunct Moxibustion; 2007.

18. Xinnong C. Chinese acupuncture and moxibustion. Beijing: Foreign Languages Press; 1987.

19. Salehian T, Safdari F, Pirak A, Kazemian A, Atarodi Z, Navabi Rigi SH. Effects of acupressure at the hugo point (LI4) on labor pain and duration of delivery in nulliparous women. Journal of Ilam University of Medical Sciences. 2011;18(4):12-19. [Persian].

20. Chao AS, Chao A, Wang TH, et al. Pain relief by applying transcutaneous electrical nerve stimulation (TENS) on acupuncture points during the first stage of labor: a randomized double-blind placebo-controlled trial. Pain. 2007;127(3):214-220. doi:10.1016/j.pain.2006.08.016

21. Sehhatie-Shafaie F, Kazemzadeh R, Amani F, Heshmat R. The effect of acupressure on sanyinjiao and hugo points on labor pain in nulliparous women: a randomized clinical trial. J Caring Sci. 2013;2(2):123-129. doi:10.5681/ jcs.2013.015

22. Ebrahimzadeh Zagami S, Golmakani N, Saadatjoo SAR, Dadgar S, Baghbani B. Comparison of effects of hyoscine n-butyl bromide and promethazine on length of active phase of first stage of labor. The Iranian Journal of Obstetrics, Gynecology and Infertility. 2012;15(6):16-21. [Persian].

23. Heydari P, Mozhdeh F, Masloum SR, Tanbakouei K, Joudaki K. Effect of SP6 acupressure on length of labor. Iranian Journal of Obstetrics and Gynecology. 2008;11(2):15-22. [Persian].

24. Kim YR, Chang SB, Lee MK, Maeng WJ. Effects on labor pain and length of delivery time for primipara women treated by san-yin-jian (SP-6) acupressure and hobgog (LI-4) acupressure. Korean J Women Health Nurs. 2002;8(2):244-56.

25. Hamidzadeh A, Shahpourian F, Orak RJ, Montazeri AS, Khosravi A. Effects of LI4 acupressure on labor pain in the first stage of labor. J Midwifery Womens Health. 2012;57(2):133-138. doi:10.1111/j.1542-2011.2011.00138.x

26. Kaviani M, Ashoori M, Azima S, Rajaeifard A, Hadianfard M. Comparing the effect of two methods of acupressure and ice massage on the pain, anxiety levels and labor length in the point LI-4. The Journal of Shahid Sadoughi University of Medical Sciences. 2012;20(2):220-228. [Persian].

27. Makvandi S, Tadayon M, Abbaspour M. Study on effect of hyoscine-N-butyl bromide suppository on pain and progress of labor. Sci Med J 2011;10(3):335-344. [Persian].

(c) 2019 The Author (s); This is an open-access article distributed under the terms of the Creative Commons Attribution License (http://creativecommons.org/licenses/by/4.0), which permits unrestricted use, distribution, and reproduction in any medium, provided the original work is properly cited. 